\section{Science decided by committee?}

SIR - Relativism has at last reached the pages of Nature. In her review of a book by $\mathbf{K}$. J. Carpenter on the history of nutrition, Sally M. Horrocks quotes with approval his conclusion that scientific fact is no longer the result of individual endeavour of a single decisive experiment, but of negotiations of committees whose "democratic approach to truth is a contradiction in terms" (Nature 372, 329; 1994). I'm sorry to hear that research in nutrition is in such a sorry state. But then Horrocks goes on to say the same is essentially true of all science, as has been demonstrated by the sociologists of science. She apparently supports the relativist view that science is merely a social construct and also believes that "scientific truth has lost its innocence and purity and has become tainted by association with forces outside its control". Such corruption is seen "as a fundamental part of the creation of new scientific facts and ideas".

I am one of those to whom she refers who attack "vehemently" the relativist approach to the sociology of science. Of course science is a social process with many and complex influences. But the validity of scientific ideas has, in the long run, nothing to do with these influences. They stand on their ability to explain nature. My questions, then are these. Does she really believe that the structure of DNA or the genetic code was settled by a committee, corrupt or otherwise? Which papers that Nature publishes conform to her relativist stance? Is the whole of modern molecular biology merely a social conspiracy?

Lewls Wolpert

Department of Anatomy

and Developmental Biology,

University College of

London Medical School,

Cleveland Street, London W1P 6DB, UK

\section{Animal research}

SIR - In your description of the future supply of primates for European interests (Nature 372, 120; 1994) you wrongly state that the Primate Vaccine Evaluation Network (PVEN) was set up in order to meet the implications of moves by the European Commission (EC)'s environment directorate on the import and use of primates in research.

We write as joint coordinators of PVEN, a joint initiative of the Biomedical Primate Research Centre, Rijswijk, the Fundacion Centro de Primates, Cali, and the $\mathrm{EC}$ research directorate. It was founded to help improve the standards and capability for high quality non-human primate research in source countries, emphasizing research on major health problems of direct relevance to developing countries. The focus is therefore on a particular set of health problems.

Commitment to high standards for animal welfare and stringent criteria for acceptable origins of animals to be used in research are central issues in a set of guidelines shortly to be published by PVEN. Membership of PVEN will entail an accreditation process based upon these guidelines. While cooperation between PVEN, the European Primate Resources Network (EUPREN) and the EC environment directorate, based upon this accreditation, is expected to ensure that primate importation complies with new directives, it is vital to recognize that this is secondary to the main aim of PVEN.

A. W. Thomas

PVEN,

Biomedical Primate Research Centre, Postbox 5815, 2280V Rijswijk,

\section{The Netherlands}

\section{S. Hererra}

Fundacion Centro de Primates,

Departamento de Microbiologicia,

Facultad de Salud,

Universidad del Valle,

Cali, Columbia

SIR - Toni Feder ${ }^{1}$ quotes Ray Guillery on plans to back animal research through education of "the public, particularly schoolchildren, about the importance and necessity of animal research".

As a scientist, I have myself carried out vivisectionist experimentation using oocyte micro-injection technology to produce transgenic animals ${ }^{2,3}$. I am currently involved in similar applications on humans, setting up an intracytoplasmic sperm injection (ICSI) facility in a clinical in vitro fertilization (IVF) programme. The experience of having injected thousands of mouse eggs turns out to have been invaluable for my work: trying to help almost azoospermic patients become parents by ICSI-IVF.

As a democratic Athenian, I am nevertheless horrified at the idea of any "scientific group" ("research lobby" is the word Feder actually uses), planning to "educate the public, particularly schoolchildren". Considering the overwhelming influence scientists already have in determining how science is taught, I am more concerned that animal rights' groups do not have sufficient opportunity to "educate" schoolchildren. This is not just unfair, it is also not democratic.

Democracy and science are (still) based on plurality and free circulation of information and opinions. All citizens should learn at school how to make objective judgements about social and ethical issues, future scientists in particular. In this (democratic?) world of lobbied, competitive science, one is then forced to ask a simple question: how can one expect schoolchildren to become scientists if they are to be conditioned by an education which includes indoctrination on the "merits" of animal research?

H. E. Cazlaris

23 Stratiotikou Syndesmou St, 106 73Athens, Greece

\section{Feder, T. Nature 372, 6 (1994). \\ 2. Keffer, J. etal. EMBOJ. 10, 4025 (1991)}

3. Probert, L. et al. J. Immun. 151, 1894 (1993).

\section{Malaria menace}

SIR - A recent article in Nature ${ }^{1}$ comments on gaps in molecular biology in several areas, including malaria. There seems to be some ignorance about the availability of antibiotics in the context of cerebral malaria. Antimalarial drugs are different from antibiotics, which are seldom effective against malaria. So there is a need for the development of more effective antimalarial drugs.

The recent outbreak of cerebral malaria in Rajasthan (India) proved fatal because the affected population had been exposed to the parasite for the first time. The outbreak has been attributed to the construction of a canal which provided mosquito-breeding sites because of waterlogging nearby ${ }^{2}$. At the same time, many of those working on the canal came from parts of the country where malaria is endemic, and were thus the source of disease transmission. The onslaught on the immune system of the local population resulted in many deaths.

A great deal of work still needs to be done to study the host and parasite molecules. In this context, we have earlier isolated and sequenced the knob protein gene that induces protuberances on the surface of infected erythrocytes through which they adhere to the cerebral capillaries and are thus partly responsible for cerebral malaria ${ }^{3-6}$. Our recent data on the knob protein gene show that there are at least two alleles of this gene in the Indian Plasmodium falciparum isolates. One of these alleles is rare whereas the other has a frequency of about 1:8. The major sequence variations occur in the immunogenic domain but there are also certain random point mutations. We still have to establish the correlation of these alleles with the strain of cerebral malaria in Rajasthan.

\section{Y. D. Sharma}

Department of Biotechnology,

All India Institute of Medical Sciences,

New Delhi-110029, India

1. Nature 372, 33 (1994)

2. Jain, R. Down to Earth 3, 5-7 (1994)

3. Sharma, Y. D. Nature 326, 550 (1987)

4. Sharma, Y. D. \& Kilejian, A. Molec. biochem. Parasitol. 26, 11-16 (1987).

5. Kilejian, A., Sharma, Y. D., Khouri, H. \& Naslund, L. Proc natn Acad Sci. U.S.A. 83, 7938-7941(1986).

6. Sharma, Y. D Int J. Biochem. 23, 775-789 (1991). 